ConNotas. Revista de CRítica y teo Ría literarias / Vol. IV, Núm. 6-7/ 2006

\title{
La poética del amor en "Vigilias" de O ctavio Paz
}

\author{
Dante Salgado*
}

Resumen:

En O ccidente es importante la idea de Tradición; reconstruir es reinventar, de ahí que las preguntas sobre el origen y destino del ser humano sean importantes en esta perspectiva que nos da una particular cosmovisión. La palabra se convierte, en cada intento de respuesta, en el instrumento para nombrar el mundo: para recrearlo. El sentido de la escritura es el Ser y su condición mortal, pero también sus afanes de trascendencia.

O ctavio Paz siguió la Tradición. Escribió poseído por la certeza de que el trabajo del escritor no es descubrir novedades, sino proponer nuevas visiones para mirar lo viejo.

La necesidad de escribir sobre el amor se explica en O ctavio Paz, además de por una clara conciencia de que seguía la Tradición, también como una respuesta, como una incomodidad, como una crítica a la época que le tocó vivir.

En "Vigilias" aparecen sus primeras reflexiones sobre el amor. Si la moral moderna, con su idea de pecado, creó una sociedad racionalista, acudimos ahora a un nuevo replanteamiento de la visión del amor. La literatura tiene que volver a ser, como en la antigüedad, la geografía de asombro.

En "Vigilias", O ctavio Paz delinea no sólo los temas que después desarrollará en ensayos y poemas: amor, erotismo, mujer, sino también prefigura el moralismo por el que será conocido su ensayística y que se convirtió en una marca indeleble de su escritura. "Vigilias" es la semilla de textos claves en la escritura paciana como "Carta de creencia" y L a llama doble.

* Universidad Autónoma de Baja California Sur. 
Palabras clave:

O ctavio Paz, Vigilias, Tradición y Modernidad.

Una de las maravillas de vivir es que tenemos frente a nosotros el día que anuncia el estruendo de alas y, al mismo tiempo, los diez mil años de historia que nos preceden. Somos un eslabón de la gran cadena de acontecimientos, cuyo principio y fin sigue siendo el misterio que afana a filósofos, teólogos y poetas; somos la herencia viva de los aciertos y los yerros de quienes nos antecedieron. Nuestra manera de pensar, de soñar, de desear o de amar es un reflejo de cómo lo hicieron nuestros padres y abuelos: somos la réplica y la confirmación, de manera simultánea, de anteriores generaciones; éstas justifican nuestra existencia y nosotros la de ellas.

Es cierto, sin embargo, que el hombre cambia; que a diferencia de las sociedades animales el ser humano crea, transforma o destruye. El cambio es el signo que distingue a la humanidad, pero en ese devenir de la existencia humana siempre hay un nudo que nos ata al pasado, que nos obliga a volver la mirada para reconocernos. Tenemos una doble herencia: genética y cultural: en nosotros se repiten rasgos físicos, el fenotipo, pero también conductas, formas de vivir y entender la vida. Existe una naturaleza humana, pero también un alma de los pueblos que nos identifica: cordón umbilical que al ser cortado nos libera y nos une irremediablemente con nuestros creadores.

En O ccidente es importante la idea de Tradición; gracias a ésta, el hombre recrea el pasado y al hacerlo se reinventa. La tradición le ofrece al hombre moderno una invaluable perspectiva que le permite reordenar, en forma constante, su visión del mundo. Así, la tradición no sólo se convierte en la columna vertebral de nuestra historia, sino que también se presenta como un conjunto de preguntas permanentes que el ser humano debe enfrentar para buscarles respuestas: las dudas sobre el origen y sobre el destino; preguntas que son materia de la filosofía, la religión y la poesía, y que están ligadas, de manera íntima, a la existencia del ser; dudas capitales que al provocar los afanes por desentrañar los misterios que las envuelven han construido la cosmovisión occidental. 
A lo largo de los siglos los humanistas han empleado todos los medios a su alcance para forjar respuestas sobre el devenir existencial del hombre en la Tierra. La palabra se convierte, así, en el instrumento para nombrar el mundo: para recrearlo. El sentido de la escritura es el Ser y su condición mortal, pero también sus afanes de trascendencia. Escribir es pensar, es aventurar una interpretación, objetiva o subjetiva, de la circunstancia desde la que se observa. Una línea de un tratado, de una epístola, de un poema, de un ensayo, es la confirmación de la necesidad de reconocimiento en los otros. G racias a la tradición, las generaciones se heredan sus dudas, pero también sus puntos de vista.

Una de las clases de texto que creó O ccidente, para reflexionar y argumentar, es el ensayo. Michel de Montaigne propuso un "pacto de lectura" entre el ensayista y el lector que marca la pauta para un discurso en el que el autor vuelca su yo, su más íntimo sentir, su individual interpretación del mundo, pero sin desligarse de la cadena de acontecimientos que lo atan con sus ancestros. El hecho de que cada ensayista sea el tema central de los asuntos que aborda es de capital importancia para entender que en este tipo de escritura el tema es el pretexto para conocer la tensión del espíritu de quien escribe.

O ctavio Paz siguió la Tradición. Escribió ensayos poseído por la certeza de que el trabajo del escritor no es descubrir novedades, sino proponer nuevas visiones para mirar lo viejo. En este sentido, el ensayo es un molde que ofrece absoluta libertad para pensar, para reflexionar, para interpretar, para problematizar. El ensayo de O ctavio Paz, tanto en su nivel semántico como en el sintáctico, es producto de la tradición occidental. Paz recoge lo sembrado por sus antecesores y continúa el debate añejo que, desde siglos atrás, ha ocupado a las mejores inteligencias; el ensayo le sirve para retomar las dudas consustanciales a la humana condición y para intentar respuestas; él reactualiza las preguntas de siempre y desde su condición de hombre moderno forja las tentativas que constituyen su obra en prosa.

La necesidad de escribir sobre el amor se explica en O ctavio Paz no sólo como un acto reflejo de su conciencia de que seguía la 
Tradición, sino también como una respuesta, como una incomodidad, como una crítica a la época que le tocó vivir.

El siglo XX fue un periodo convulso; escenario de revoluciones y guerras mundiales, fue también el tiempo del fin de las utopías y del ocaso de la modernidad. Y como en cada final de ciclo, el hombre enfrentó una profunda crisis existencial que aún no resuelve.

La modernidad, que arranca más o menos desde finales del siglo XVIII, señala Paz en L os hijos del Limo (1974), es el tiempo de la escisión y de la negación de sí mismo, el tiempo de la crítica. La modernidad se identificó con el cambio, identificó al cambio con la crítica y a los dos con el progreso" (210). El futuro fue erigido como ideal de vida, como el punto hacia el que tenía que encaminarse la humanidad, a despecho de la idea cristiana medieval de que en el futuro, el creyente esperaba el Juicio Final, en donde se resolvería su salvación 0 condenación eternas.

El progreso se convierte en una demencial carrera hacia un mañana que nunca llega; el futuro es el último eslabón de la cadena infinita de la historia. El tiempo es una línea sucesiva y progresiva. Pero la modernidad también produjo un espíritu crítico como rasgo distintivo: incesante dialéctica de negación y afirmación que Paz llama "tradición de la ruptura". El pensamiento moderno niega a la modernidad, pero al negarla la confirma.

Después de la Segunda G uerra Mundial, todas estas ideas que parecían inquebrantables ceden ante la duda que despierta el engañoso futuro:

En los últimos años ha habido un cambio brusco: los hombres empiezan a ver con terror el porvenir y lo que apenas ayer parecían las maravillas del progreso hoy son sus desastres. El futuro ya no es el depositario de la perfección, sino del horror. (213)

La idea de cambio que enarboló la modernidad ha tenido que ceder terreno a la de conservación ante las aterradores estadísticas sobre la devastación del planeta. Y aunque todavía hay resistencias visibles en las grandes potencias económicas, la idea de progreso se 
fisura, pues es inocultable la vergonzosa desigualdad que hay en el mundo. La demografía y la ecología arrojan cifras alarmantes y nos hacen pensar en un mañana difícil. El presente - dice Paz- hace la crítica del futuro y empieza a desplazarlo.

Esta crítica, aunque producto de la modemidad, es, en realidad, su colofón: "Ahora, en la segunda mitad del siglo XX, aparecen ciertos signos que indican un cambio en nuestro sistema de creencias. La concepción de la historia como un proceso lineal progresivo se ha revelado inconsistente" (212).

La mutación de la sensibilidad para percibir el tiempo actual significa una renuncia a las ideas que durante siglos sostuvo la modernidad. La moral, del ahorro y del trabajo, necesaria para alcanzar el deseado futuro se ha resquebrajado: "La sublevación de los valores corporales y orgiásticos es una rebelión contra la doble condenación del hombre: la condena al trabajo y la represión del deseo" (218).

Para la modernidad, el cuerpo dejó de ser el templo del espíritu y se convirtió en fuerza de producción. La capacidad para el trabajo desplazó, dentro del cuerpo, al placer. Pero con el declive de la modernidad el cuerpo recupera un sitio de privilegio y el placer deja de verse como un gasto inútil y la sensualidad como perturbadora. La insurrección del cuerpo - afirma Paz- incluye a la de la imaginación y ambas niegan al tiempo lineal: cuerpo e imaginación reivindican el presente.

La resurrección del cuerpo quizás es un anuncio de que el hombre recobrará alguna vez la sabiduría perdida. Porque el cuerpo no solamente niega el futuro: es un camino hacia el presente, hacia ese ahora donde vida y muerte son las dos mitades de una misma esfera. (219)

D os ideas importantes se desprenden de esta cita: la instauración del instante como el tiempo sin tiempo del amor y la conciliación de contrarios, ambas de cuño romántico; ninguna de las dos se entendería sin la participación de la imaginación. 
El tiempo lineal de la modernidad cede el paso a una idea cíclica del transcurrir; el ser humano se instala en el presente, en el ahora, en el instante, en donde los opuestos complementarios se convierten en "las dos mitades de una misma esfera".

$\mathrm{El}$ hecho de que Paz se refiera, de manera particular, al binomio vida-muerte está cargado de simbolismo; al hacerlo reactualiza la sed metafísica de unidad y la aspiración de trascendencia, con claros ecos platónicos y románticos.

En una de sus primeras prosas, "Vigilias I" - en septiembre de 1935-, escribió:

¿Quién conocerá los límites de la muerte? ¿Q uién los del amor? ¿Q ué línea, qué estrella, los separa? Sus aguas se juntan en un solo sitio, más allá de todo tiempo [...] A través del amor [...] palpamos a la muerte [...] Pero la muerte no es el fin del amor, sino su condición, su entraña, y exigencia: la muerte sólo vive del amor y él sólo de ella. ¿Q uién, al amar, no siente el morir, ya como abandono, ya como avidez? El amor nos sepulta en la nada; por él sabemos del vacío y de la extinción de lo humano consciente en el terrible, inacabable fluir de la muerte. (Primeras letras 67)

Es éste un fragmento de filiación romántica inocultable. El joven Paz, de apenas veintiún años, deja entrever que su visión sobre el amor recoge los ecos del romanticismo pesimista de Goethe y Novalis. La muerte no es el fin sino una salida hacia otro lugar en donde sí es posible la perfección y el amor auténtico. El amor y la muerte facilitan una vía de acceso a otro mundo: son las condiciones extremas que aproximan al ser humano a la experiencia de lo inefable, en donde morir es vivir.

Si bien las prosas que integran "Vigilias" ${ }^{1}$ no son técnicamente ensayos, es aquí en donde aparecen las primeras reflexiones sobre

${ }^{1}$ Estas prosas se recogen en la colección Primeras letras (1931-1943), publicado en 1988 por editorial V uelta. 
el amor. ${ }^{2}$ Paz cree que aceptar la muerte es aceptar el tiempo presente. El hombre inventó las eternidades y los futuros - sostienepara escapar de la muerte; pero en la ilusión de la huida terminó perdido en los laberintos de la razón. Aceptar el ahora, en cambio, reconcilia al ser humano con su realidad terrena: con su condición finita. El presente obliga a ver de frente a la muerte, pero no como opuesta a la vida, sino como su otra media cara. Así, el final que es morir puede ser también un inicio; principio y fin constituyen, entonces, "las dos mitades de una misma esfera".

El ahora ha sido siempre el tiempo de los poetas y de los enamorados, de los epicúreos y de algunos místicos. El instante es el tiempo del placer pero también el tiempo de la muerte, el tiempo de los sentidos y el de la revelación del más allá. (L a otra voz. Poesía y fin de siglo 53)

Amar es morir, afirma Paz, pero también es un nacimiento. El acto amoroso concilia los extremos, nacer y morir, que vuelven precaria la condición humana. Amar es experimentar, en un instante fugaz pero intenso, el ciclo vital; ese instante suspendido en el que se concilian los opuestos, en el que se mira a la muerte cara a cara, es el tiempo del amor. Ese instante que se desprende de la línea temporal progresiva puede durar un segundo o todos los siglos. Lo natural conduce a lo sobrenatural, la duración a lo intemporal. El amor, como la poesía, es fuente de revelación; el amor produce otra realidad, en donde la conciliación de contrarios y la anulación del tiempo lineal es posible.

Adán y Eva son la pareja, todas las parejas, el amor que se sueña eterno y en el que siempre comienza la especie; el amor no como quisiéramos que fuera, no como lo soñamos, sino como es, en estado de pura existencia, desnudo de toda acechanza mortal. (Primeras letras 76)

${ }^{2}$ El 11 de marzo de 2002 el periódico Reforma publicó, en su sección de cultura, 
La referencia al mito bíblico sobre el origen del hombre ubica a Paz en la tentativa por recobrar la visión adánica del amor; él cree en una edad de oro en la que existió un ser perfecto, libre de pecado, completo. Un ser para el que, antes de la caída y el destierro, no tienen sentido las palabras escisión, soledad y muerte.

El dilema al que se enfrenta Paz es que ese hombre primero, esencia de la vida, es sólo una intuición, una reminiscencia, un deseo. No obstante, aun sin haber existido, Adán y Eva son la pareja que reviven los enamorados, los amantes; y cada vez que se pronuncia un "te amo" se crea el mundo.

Sin embargo, la modernidad cambió la salvación y la gracia por la moral y la razón, renunció al amor y se entregó al dinero que: "No tiene ningún sabor terrenal. No sirve para nada, puesto que no se dirige a nada. Pero todos son sus servidores. $Y$ todos giramos en su órbita, sin salida alguna, en un mundo sin principio ni fin, vacío" (Primeras letras 79).

El dinero es una medida del tiempo, el tiempo del trabajo y éste del cuerpo. Pero el dinero es un signo hueco que no ofrece respuestas a las dudas capitales del ser. Si preguntamos ipor qué morimos o por qué amamos?, la modernidad, con todo su dinero y toda su capacidad racional, se pasma. Nadie sabe para qué vive o para qué muere. El amor se convierte, en medio de la debâde existencial de la modernidad, en una opción para reorientar la conciencia humana;

una noticia titulada "Revela Paz en cartas su amor por G arro", en la que se informa sobre la existencia de 23 epístolas inéditas escritas por $\mathrm{O}$ ctavio Paz a Elena $\mathrm{G}$ arro entre el 21 de julio y el 15 de octubre de 1935 y que suman, al decir de la nota periodística, 180 páginas; se adelanta el contenido de las cartas: "Las reflexiones sobre la naturaleza del amor son una constante en estas misivas escritas con una caligrafía "imposible", casi febril...". Por las fechas atribuidas a las cartas, éstas fueron escritas un poco antes que "Vigilias I", firmada en septiembre de 1935, lo que me obliga a matizar la afirmación que da pie a esta nota. También E 1 U niversal, en el suplemento cultural "Confabulario" del día 24 de abril de 2004, da cuenta de la correspondencia antes referida sin agregar nada extraordinario a lo que ya se había dicho en Reforma. 
para que actos tan cotidianos como nacer, morir, llorar o trabajar despierten de nuevo nuestra capacidad de asombro.

El hombre -dice Paz en Las peras del olmo (1957)- es la única criatura que siente amargura y vergüenza de existir; y a esta desolada conciencia se debe la generación de la cultura, la filosofía y la moral; por esta última es posible domeñar el temperamento pero, de manera simultánea, dejar que fluya lo más profundo del ser que justifica los actos personales.

El hombre, por definición, es aquel ser que duda, reniega, abdica, cede y, en fin, se afirma ante los otros, inclusive cuando se niega. Y ese elemento imprevisible, núcleo secreto e incógnito siempre, es el que hace hombre a cada hombre. (197)

Como efecto de nuestra condición humana conocemos la introspección y el mirarse a sí mismo despierta el "sentido moral". La reflexión es un acto de libertad que nos devuelve íntegros al centro de la existencia.

El ensayo, como categoría escritural, es una clase de texto que da cauce a esta necesidad de autoexploración, de autoconocimiento. El ensayo amoroso de Paz es una radiografía de la moral colectiva; es una bitácora de lo que él llama "sentimiento de culpa", presente en las mejores obras de la literatura.

Si la moral moderna, con su idea de pecado, creó una sociedad racionalista, acudimos ahora a un nuevo replanteamiento de la visión del amor. La literatura tiene que volver a ser, como en la antigüedad, la geografía del asombro, "el silencio y el balbuceo del hombre, acostumbrado al monólogo misterioso, carnal de la sangre" (Primeras letras 90).

Paz afirma que la nueva moral sexual despoja al sexo del velo de pecado y misterio que lo cubría, pero sin abandonar su carga racionalista, siempre temerosa de la seducción de la sensualidad. Propone un "nuevo" romanticismo que se construya en la comunión:

Romanticismo que no enarbola la bandera de la pasión individual, del sentimiento oprimido, del yo en libertad, como en 
el diecinueve, sino la del instinto, la de la sensación, la de lo más antiguo: esa solidaridad carnal, remota y pura que, de un modo oscuro, nos hace hermanos del hombre y nos da la clave de nuestra semejanza bajo la gran noche amenazante. (Primeras letras 90)

Para materializar esta propuesta se necesita una nueva moral que eduque tanto a los sentidos como a los sentimientos. La integridad del hombre debe incluir la integridad sensual, perdida o pervertida por el mercantilismo atroz que ha dominado a Occidente en las últimas décadas.

Para acceder al amor se necesita tener conciencia de sí; el punto de partida es lo que Paz llama el "dolor del ser", es decir, saber que estamos solos pues el amor se alimenta de absoluto y eternidad. Amar es, entonces, la comunión de soledades, el encuentro con la pareja, tan viva y tan frágil que también comparte la angustia de la existencia.

De este conocimiento de la fugacidad de la vida parte el deseo de comunión, la necesidad de trascendencia, pues "Amar es dar un salto mortal"; amar es reconocerse en el otro y "comprender que la mujer no es el fantasma que nuestro deseo finge, sino el ser vivo que nuestra avidez necesita" (Primeras letras 90).

Por medio de la mujer, sostiene el poeta, el mundo se vuelve visible; el amor opera la revelación, el conocimiento de lo que no se ve a simple vista. Pero la moral moderna, con su idea de virtud, no ha entendido que una moral de pasiones débiles es una moral de hombres débiles. No debe confundirse, aclara Paz, la exaltación de la sensualidad con la fanfarronería de los instintos. No debemos temer a la fidelidad porque desde la Grecia clásica virtud puede entenderse no como la supresión del deseo sino como su dominio.

En "Vigilias", O ctavio Paz delinea no sólo los temas que después desarrollará en ensayos y poemas: amor, erotismo, mujer, sino también prefigura el moralismo por el que será conocido en su ensayística y que se convirtió en una marca indeleble de su escritura.

Sobre su poética amorosa puedo decir una frase dicha por él mismo, en estas sus primeras prosas, que bien puede aplicarse a 
toda su obra creativa y sintetiza la congruencia de su pensamiento sin momificarlo: "Cambiar y ser uno mismo siempre" (Primeras le tras 92).

\section{Bibliografía}

Paz, O ctavio. L a otra voz: poesía y fin de siglo. Barcelona: Seix Barral, 1990.

. L as peras del olmo. Barcelona: Seix Barral, 1986.

. L os hijos del limo. Barcelona: Seix Barral, 1974.

. Primeras letras (1931-1943). México: Vuelta, 1988. 